\title{
Penerapan model pembelajaran ADDIE untuk meningkatkan keterampilan proses sains siswa pada materi kinematika gerak lurus
}

\author{
${ }^{1}$ Haris Rosdianto, ${ }^{1}$ Emi Sulistri, ${ }^{1}$ Nasa Munandar \\ ${ }^{1}$ Prodi Pendidikan Fisika, STKIP Singkawang, Kota Singkawang 79151, Indonesia \\ e-mail: harisrosdianto@yahoo.com; sulistriemi@gmail.com; nasamunandar9@gmail.com
}

\begin{abstract}
Abstrak
Penelitian ini bertujuan untuk mendeskripsikan peningkatan keterampilan proses sains siswa setelah diterapkan model pembelajaran ADDIE. Penelitian ini merupakan jenis penelitian kuantitatif dengan metode quasy exsperiment dan menggunakan desain penelitian nonequivalent control group design. Populasi dalam penelitian ini adalah semua siswa kelas VIII di salah satu SMP Negeri 8 Singkawang. Sedangkan sampel dalam penelitian ini adalah kelas VIII A yang diambil dengan menggunakan teknik simple random sampling. Peningkatan keterampilan proses sains diukur dengan menggunakan 14 soal pilihan ganda beralasan. Dari analisis dengan menggunakan $\mathrm{N}$-gain, diperoleh peningkatan keterampilan proses sains sebesar 0,56 dengan kategori sedang. Oleh karena itu, model pembelajaran ADDIE dapat menjadi solusi dalam peningkatan keterampilan proses sains siswa.
\end{abstract}

Kata Kunci: Model Pembelajaran ADDIE; Keterampilan Proses Sains; Kinematika Gerak Lurus

\section{Application of ADDIE learning models to improve students' science process skills in} linear motion kinematics material

\begin{abstract}
This study aims to describe the improvement of students' science process skills after ADDIE learning model was implemented. This type of this research is quantitative research with quasy exsperiment method and use nonequivalent control group design research. The population in this study is all students of class VIII from SMP Negeri 8 Singkawang. The sample in this study is class VIII A by using simple random sampling technique. The improvement of Science Process Skills was measured using 14 multiple-choice questions with argument. From the analysis by using N-gain, obtained that students' Science Process Skills was improved by 0.56 with medium category. Therefore, the ADDIE learning model can be a solution in improving students' science process skills.
\end{abstract}

Keywords: ADDIE Learning Model; Science Process Skills; Straight Line Motion Kinematics

How to Cite: Rosdianto, H., Sulistri, E., \& Munandar, N. (2019). Penerapan Model Pembelajaran ADDIE Untuk Meningkatkan Keterampilan Proses Sains Siswa Pada Materi Kinematika Gerak Lurus. Jurnal Pendidikan Fisika dan Keilmuan (JPFK), 5(1), 53-58. doi:http://dx.doi.org/10.25273/jpfk.v5i1.2947

\section{PENDAHULUAN}

Temuan ilmu sains khususnya fisika didapat berdasarkan pengamatan terhadap berbagai fenomena alam. Dari pengamatan yang dilakukan, akan menimbulkan rasa ingin tahu yang dibuktikan berdasarkan rancangan penyelidikan yang kemudian ditindaklanjuti untuk mencari penjelasan akurat dan konsisten terhadap fenomena-fenomena alam dan secara langsung dapat melatihkan maupun mengembangkan keterampilan proses sains (Erina \& Kuswanto, 2015; Muslim \& Tapilouw, 2015; Semiawan, 1992). Keterampilan proses sains merupakan keterampilan untuk menguasai kemampuan dan keterampilan fisik 
serta mental tertentu untuk mendapatkan penemuan baru (Aji, Santosa, \& Probosari, 2014; Rustaman et al., 2005; Semiawan, 1992). Keterampilan proses sains terbagi menjadi dua jenis yaitu keterampilan proses sains dasar dan keterampilan proses sains terintegrasi. Keterampilan proses dasar merupakan keterampilan proses yang bertujuan untuk menemukan konsep-konsep baru (Rezba, Sprague, \& Fiel, 2003). Keterampilan proses dasar meliputi kegiatan observasi, klasifikasi, mengukur, mengomunikasikan, menafsirkan, memprediksi, menggunakan alat, melakukan percobaan, dan menyimpulkan (Kemendikbud, 2016). Keterampilan ini memberikan dasar intelektual dalam penyelidikan ilmiah (Karamustafaoğlu, 2011). Sedangkan keterampilan proses terintegrasi merupakan keterampilan merancang investigasi untuk menguji suatu konsep (Rezba et al., 2003). Keterampilan proses terintegrasi meliputi kegiatan merumuskan masalah, mengidentifikasi variabel, mendeskripsikan hubungan antar variabel, mengendalikan variabel, mendefinisikan variabel secara operasional, memperoleh dan menyajikan data, menganalisis data, merumuskan hipotesis, merancang penelitian, dan melakukan percobaan (Kemendikbud, 2016). Keterampilan ini memberikan pemecahan masalah atau melakukan percobaan sains (Karamustafaoğlu, 2011).

Ada beberapa alasan yang melandasi perlunya keterampilan proses sains, diantaranya adalah karena semakin cepatnya perkembangan ilmu pengetahuan sehingga tidak memungkinkan guru untuk mengajarkan semua fakta dan konsep kepada siswa (Semiawan, 1992), pemahaman konsep yang rumit dan abstrak akan lebih mudah jika disertai contoh nyata yang sesuai (Rosdianto \& Murdani, 2017), serta dapat mengembangkan sikap dan nilai dalam diri siswa (Semiawan, 1992). Akan tetapi, terdapat berbagai kendala yang dapat menghambat pengembangan keterampilan proses sains, diantaranya dikarenakan perolehan pengetahuan yang hanya berdasarkan pada pemberian informasi (Sanjaya, Murda, \& Arcana, 2014). Selain itu, penggunaan model pembelajaran konvensional juga menjadikan siswa kurang berperan aktif dalam proses pembelajaran (Nurseha, 2015). Kegiatan pembelajaran yang cenderung pasif tidak dapat mencapai tujuan pembelajaran yang seharusnya konsisten dengan hakikat sains (Retnaningati \& Sugiharto, 2013; E Sulistri, 2016; Emi Sulistri \& Nugroho, 2018). Sama halnya dengan hasil prariset yang telah dilakukan di SMP Negeri 8 Singkawang.

Dari kegiatan observasi, siswa hanya terfokus pada guru disaat pembelajaran berlangsung walaupun proses pembelajarannya dilengkapi dengan alat peraga. Dari kegiatan wawancara, didapat bahwa guru lebih terfokus pada lembar kerja siswa yang menjadi alat ukur tingkat hasil belajar, sedangkan keterampilan siswa berdasarkan kegiatan eksperimen masih belum pernah dilatihkan. Selain itu, dari hasil tes soal keterampilan proses sains yang diberikan kepada 4 dari 6 kelas, didapat bahwa nilai rata-rata siswa sangat rendah. Rendahnya hasil tes dikarenakan siswa tidak dilatihkan berbagai keterampilan proses dasar, diantaranya adalah keterampilan observasi, hipotesis, klasifikasi, menggunakan alat atau bahan, menerapkan, menafsirkan, dan komunikasi. Selain itu, akibat rendahnya keterampilan proses sains siswa akan berdampak pada pengembangan ilmu pengetahuan. Hal ini dikarenakan keterampilan proses sains dapat melatihkan penemuan suatu pengetahuan atau informasi berdasarkan kegiatan eksperimen (Semiawan, 1992).

Oleh karena itu, perlunya pendekatan dalam suatu model pembelajaran yang dapat melatihkan keterampilan proses sains siswa berdasarkan kegiatan eksperimen. Banyak model pembelajaran yang dapat digunakan, satu diantaranya 
adalah model pembelajaran ADDIE. Model pembelajaran ADDIE merupakan model pembelajaran yang berpusat pada siswa dan dapat memfasilitasi siswa dalam mengembangkan proses sains berdasarkan tahapan yang sistematis (Aldoobie, 2015; Arkün \& Akkoyunlu, 2008; McGriff, 2000). Adapun tahapan model pembelajaran ADDIE adalah analysis, design, develop, implement, evaluate (Aldoobie, 2015). Pada tahap analysis, merupakan tahap identifikasi untuk mencapai tujuan pembelajaran. Tahap kedua adalah design yang merupakan rancangan pembelajaran yang efektif agar mempermudah proses pembelajaran. Tahap ketiga adalah development yang dilakukan dengan mengembangkan suatu pembelajaran berdasarkan bahan pendukung. Tahapan selanjutnya adalah tahap implement berdasarkan penerapkan bahan pendukung untuk menyampaikan tingkat efektifitas dan efisien dari pembelajaran. Tahap terakhir adalah tahap evaluate yang bertujuan untuk Meningkatkan, melanjutkan, atau menghentikan dalam pencapaian tujuan pembelajaran (Aldoobie, 2015; McGriff, 2000).

\section{METODE PENELITIAN}

Penelitian ini merupakan jenis penelitian kuantitatif, dengan bentuk quasy experiment. Design penelitian yang digunakan adalah nonequivalent control group design. Selain itu, populasi dalam penelitian ini adalah semua siswa kelas VIII di SMP Negeri 8 Singkawang dan sampelnya adalah kelas VIII A. Teknik pengambilan sampel dalam penelitian ini adalah random sampling.

Teknik pengumpulan data dalam penelitian ini menggunakan instrumen berbentuk lembar tes keterampilan proses sains. Lembar tes yang diberikan berupa 14 soal pilihan ganda beralasan yang telah diujicobakan. Lembar tes tersebut diberikan kepada sampel pada saat pretest dan postest. Hasil tes kemudian dianalisis dengan menggunakan rumus $\mathrm{N}$-gain sebagai berikut:

$$
<g>=\frac{N_{\text {Post-test }}-N_{\text {Pr } e-t e s t}}{N_{\text {Maksimum }}-N_{\text {Pr e-test }}}
$$

Adapun kriteria Gain Skor sebagai berikut:

Tabel 1. Kriteria Gain Skor

\begin{tabular}{ccc}
\hline Indeks gain & Kategori \\
\hline$<g>\geq 0,7$ & Tinggi & \\
\hline $0,3 \leq<g><0,7$ & Sedang & \\
\hline$<g><0,3$ & Rendah & \\
\hline & \multicolumn{2}{c}{ (Hake, 1998) }
\end{tabular}

\section{HASIL DAN PEMBAHASAN}

Dari hasil penelitian yang dilakukan diperoleh peningkatan setiap aspek keterampilan proses sains dengan menggunakan $\mathrm{N}$-gain sebagai berikut: 


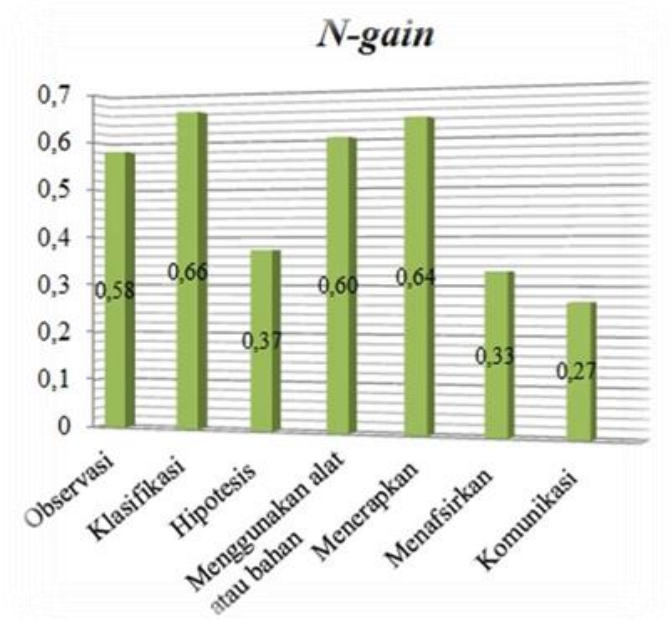

Gambar 1. Grafik Skor N-gain setiap aspek keterampilan proses sains

Dari analisis $\mathrm{N}$-gain, didapat bahwa rata-rata peningkatan keterampilan proses sains adalah sebesar 0,56 dengan kategori sedang. Selain itu, setiap aspek keterampilan proses sains juga mengalami peningkatan. Pada aspek hipotesis yang diterapkan pada tahap analysis mengalami peningkatan sebesar 0,37 dengan kategori sedang. Peningkatan aspek hipotesis dikarenakan siswa mampu menjelaskan pengamatan sebelum dilakukannya kegiatan eksperimen (Siradjuddin, Rosdianto, \& Sulistri, 2018). Pada aspek menggunakan alat atau bahan yang dilakukan pada tahap design dan development mengalami peningkatan sebesar 0,60 dengan kategori sedang. Peningkatan aspek menggunakan alat atau bahan dikarenakan siswa mengetahui fungsi dan cara kerja alat (Purbasari, 2013). Pada aspek menerapkan dilakukan pada tahap implement dan mengalami peningkatan sebesar 0,64 dengan kategori sedang. Peningkatan aspek menerapkan dikarenakan siswa dapat menggunakan konsep pada pengalam baru (Semiawan, 1992). Pada aspek menafsirkan dilakukan pada tahap evaluate dan mengalami peningkatan sebesar 0,33 dengan kategori sedang. Peningkatan pada aspek menafsirkan dikarenakan siswa mampu mengumpulkan data hasil pengamatan dan pengukuran saat melakukaan kegiatan eksperimen (Siradjuddin et al., 2018). Pada aspek komunikasi yang dilakukan pada tahap evaluate merupakan aspek keterampilan proses sains yang mengalami peningkatan paling rendah diantara aspek keterampilan proses sains yang diukur, yaitu 0,27 dengan kategori rendah. Rendahnya peningkatan pada aspek komunikasi dikarena siswa masih belum terlatih pada perubahan bentuk data empiris hasil percobaan atau pengamatan ke dalam bentuk table, grafik diagram atau bentuk lainnya. Selain itu, besar peningkatan pada aspek komunikasi dikarenakan siswa lebih aktif mengikuti kegiatan pembelajaran (Wahyudi, 2015). Dari peningkatan setiap aspek keterampilan proses sains siswa, dapat dikatakan bahwa model pembelajaran ADDIE dapat meningkatkan keterampilan proses sains siswa.

\section{KESIMPULAN}

Dari hasil dan pembahasan, dapat disimpulkan bahwa keterampilan proses sains siswa meningkat setelah diterapkan model pembelajaran ADDIE dengan indeks $\mathrm{N}$-gain sebesar 0,56 dengan kategori sedang. 


\section{DAFTAR PUSTAKA}

Aji, A. C., Santosa, S., \& Probosari, R. M. (2014). Pengaruh Model Pembelajaran Inkuiri Terbimbing Berbasis Joyful Learning (Interjoy) terhadap Keterampilan Proses Sains Siswa Kelas X SMA Negeri 2 Surakarta Tahun Pelajaran 2012/2013. Bio-Pedagogi, 3(1), 23-36.

Aldoobie, N. (2015). ADDIE model. American International Journal of Contemporary Research, 5(6), 68-72.

Arkün, S., \& Akkoyunlu, B. (2008). A Study on the development process of a multimedia learning environment according to the ADDIE model and students' opinions of the multimedia learning environment. Interactive educational multimedia: IEM(17), 1-19.

Erina, R., \& Kuswanto, H. (2015). Pengaruh model pembelajaran instad terhadap keterampilan proses sains dan hasil belajar kognitif fisika di SMA. Jurnal Inovasi Pendidikan IPA, 1(2), 202-211.

Hake, R. R. (1998). Interactive-engagement versus traditional methods: A sixthousand-student survey of mechanics test data for introductory physics courses. American journal of Physics, 66(1), 64-74.

Karamustafaoğlu, S. (2011). Improving the science process skills ability of prospective science teachers using I diagrams. Eurasian Journal of Physics and Chemistry Education, 3(1), 26-38.

Silabus Mata Pelajaran SMA/MA Mata Pelajaran Fisika, Kementrian Pendidikan dan Kebudayaan (Kementrian Pendidikan dan Kebudayaan 2016).

McGriff, S. J. (2000). Instructional system design (ISD): Using the ADDIE model. Retrieved June, 10(2003), 513-553.

Muslim, K., \& Tapilouw, F. S. (2015). Pengaruh Model Inkuiri IImiah terhadap Peningkatan Keterampilan Proses Sains Siswa SMP pada Materi Kalor dalam kehidupan. EDUSAINS, 7(1), 88-96.

Nurseha, N. (2015). PENGARUH MODEL PEMBELAJARAN CHILDREN LEARNING IN SCIENCE TERHADAP KETERAMPILAN PROSES SAINS DAN PEMAHAMAN KONSEP TENTANG GETARAN DAN GELOMBANG PADA KELAS VIII SMP NEGERI 5 MARAWOLA. Mitra Sains, 3(1). Retrieved from http://jurnal.untad.ac.id/jurnal/index.php/MitraSains/article/view/3865

Purbasari, D. H. N. (2013). Studi Komparasi Model Pembelajaran Open Ended-Group Investigation Dan Pembelajaran Konvensional Terhadap Kemampuan Berpikir Kreatif Dan Keterampilan Proses Sains (KPS) Biologi Siswa Kelas X SMA Negeri 8 Surakarta. Universitas Sebelas Maret,

Retnaningati, D., \& Sugiharto, B. (2013). Penerapan Model Pembelajaran Siklus Belajar (Learning Cycle) untuk Meningkatkan Keterampilan Proses Sains Siswa Kelas X-2 SMA Negeri 3 Surakarta Tahun Pelajaran 2010/2011. Bio-Pedagogi, 2(1), 53-60.

Rezba, R. J., Sprague, C., \& Fiel, R. (2003). Learning and assessing science process skills: Kendall Hunt.

Rosdianto, H., \& Murdani, E. (2017). THE IMPLEMENTATION OF POE (PREDICT OBSERVE EXPLAIN) MODEL TO IMPROVE STUDENT'S CONCEPT UNDERSTANDING ON NEWTON'S LAW. Jurnal Pendidikan Fisika, 6(1), 5557.

Rustaman, N., Dirdjosoemarto, S., Yudianto, S. A., Achmad, Y., Subekti, R., Rochintaniawati, D., \& Nurjhani, M. (2005). Strategi belajar mengajar biologi. In: Malang: UM press.

Sanjaya, I. G. R., Murda, I. N., \& Arcana, I. N. (2014). Pengaruh Model Pembelajaran SFAE Terhadap Hasil Belajar PKn Siswa Kelas VI Gugus IV Rama Jembrana. MIMBAR PGSD Undiksha, 2(1). 
Semiawan, C., Tangyong, A.F., Belen, S, Matahelemual, Y \& Suseloarjdo, W. (1992). Pendekatan Keterampilan Proses. Jakarta: Gramedia.

Siradjuddin, S., Rosdianto, H., \& Sulistri, E. (2018). Penerapan model REACT untuk meningkatkan keterampilan proses sains siswa pada materi arus listrik. Jurnal Pendidikan Fisika dan Keilmuan (JPFK), 4(1), 17-22.

Sulistri, E. (2016, 15 October 2016). The Investigation of Junior High School Students' Science Process Skill in Terms of Some Variables. Paper presented at the International Seminar on Mathmatics, Science, and Computer Education, Bandung.

Sulistri, E., \& Nugroho, S. E. (2018). The Development of Set Activity Based Assessment (ABA) to Measure Student Science Process Skill at Physics II.

Wahyudi, A. (2015). Pengaruh Problem Based Learning Terhadap Keterampilan Proses Sains dan Hasil Belajar Biologi Siswa Kelas X SMA Negeri Jumapolo Tahun Pelajaran 2013/2014. Bio-Pedagogi, 4(1), 5-11. 